\title{
DIURNAL VARIATION OF HEIGHT IN SOUTH INDIAN ADOLESCENT
} SUBJECTS

\section{Jinu Merlin Koshy ${ }^{1}$, G.Durga Devi ${ }^{2}$, Archana R *3, WM S Johnson ${ }^{4}$.}

${ }^{1}$ Reader, Department of Anatomy, Sree Balaji Dental College and Hospital, Bharath University, Chennai, Tamil Nadu, India.

${ }^{2}$ Assistant Professor, Department of Anatomy Sree Balaji Medical College and Hospital, Bharath University, Chennai, Tamil Nadu, India.

${ }^{*}$ Assistant Professor, Department of Anatomy Sree Balaji M edical College and Hospital, Bharath University, Chennai, Tamil Nadu, India.

${ }^{4}$ Professor \&HOD, Department of Anatomy Sree Balaji Medical College and Hospital, Bharath University, Chennai, Tamil Nadu, India.

\section{ABSTRACT}

The linear height of an individual is considered a reliable measure of physical growth and development. It has significant implications in medicolegal and forensic examination. The aim of the present study was to establish diurnal variation of stature in adolescent Indian subjects. A total of 60 adolescents aged between 13 years to 19 years with equal number of male and female individuals enrolled for the present study .The heights of subjects were measured at $9.00 \mathrm{hrs}$ and $16.00 \mathrm{hrs}$ using Freemans body meter measuring tape with wall stop for 5 days. The data collected was thoroughly screened and subjected to statistical analysis. Results revealed diurnal variation in height among each individual and also significant difference in diurnal variation of stature between male and female. The present study has important implication with respect to recruitment of individuals for service as well as in forensic medicine for personal identification.

KEY WORDS: Diurnal variation, stature, physical growth, anthropology, forensic medicine.

Address for Correspondence: Dr. Archana R, M Sc PhD, Assistant Professor, Department of Anatomy, Sree Balaji Medical College and Hospital, Bharath University, Chennai, Tamil Nadu, India.

E-Mail: archana09@yahoo.com

\begin{tabular}{|l|l|}
\hline \multicolumn{3}{|c|}{ Access this Article online } \\
\hline Quick Response code & Web site: International Journal of Anatomy and Research \\
ISSN 2321-4287 \\
www.ijmhr.org/ijar.htm \\
\cline { 2 - 3 }
\end{tabular}

\section{INTRODUCTION}

M an's habits are governed largely by regular environmental and social rhythms. A circadian rhythm is any biological process that displays an endogenous oscillation of about 24 hours. These 24-hour rhythms are driven by a circadian clock, and they have been widely observed by humans. Diurnal can also be used to describe something that has a daily cycle. As the word is also used to distinguish night and day; Conroy\& Mills (1970) preferred the use of circadian to indicate a period of approximately 24 hours [1]. Recently there has been a significant upsurge in interesting diurnal variation or changes especially as they relate to changes in height, the disc; and to some extent; to joint ranges.

Height is the measure of vertical distance, either how "tall" something is, or how "high up" 
it is. Height is the most often used anthropometric dimension and it is a quantitative measure of physique and indicative of physical growth and development of an individual. Anatomically, it is a composite of linear dimensions of skull, vertebral column, pelvis and legs. Diurnal variation in stature was first noted in 1726 has, however, been largely ignored in clinical practice [2]. Early studies, reviewed by Redfield and Meredith and Boyd, were conducted with varying degrees of scientific rigor, but did confirm the presence of diurnal variation in the adult $[3,4]$. Most agreed that the total loss mounted to between 2 and $3 \mathrm{~cm}$, and the evidence suggested that the greater proportion of the decrease in height was occurring in the trunk. Similar effects have been shown in children also [5-10]. Almost all studies report that stature is maximum in the morning and less by $1.5 \mathrm{~cm}$ to $3.0 \mathrm{~cm}$ in the evening, the studies further confirm that greater proportion of decrease in height is occurring in the vertebral column due to reduction of elasticity of inter-vertebral discs [3,6, 9, and 11]. Some studies showed that height can be restored by taking short naps [4.12].

The substantial effects of gravity on body height are exemplified by astronauts who apparently show increases of up to $10 \mathrm{~cm}$ on returning to earth [13]. Diurnal changes in lumbar flexion have been confirmed but only two measures were made, one in the early morning and one in the afternoon [14]. These authors interestingly found that the early morning result, taken 1.0 minutes after rising, could also be achieved up to 2 hours after rising on subsequent measures, by getting the subject to lie down before the test for a period of time equal to the time spent between rising and lying down.

The aim of the present study was to examine and confirm the diurnal variation of stature in adolescent Indian subjects.

\section{MATERIALS AND METHODS}

The data for this study were obtained from a total of 60 adolescents; aged 13-19 years. An equal number of males and females enrolled in the study with parental permission.

Written consent was obtained from all the subjects at the time of screening, and from the
Institutional Ethical committee of Sree Balaji M edical College for the study. Armamentarium: Freemans measuring tape, Recording sheet, Computer.

The heights of subjects were measured at 09:00 hrs and 16:00 hrs using Free mans Body M eter Measuring Tape with Wall Stop for 5 days. During the 5 days period, the stature of each subject was recorded by the same observer to avoid inter-observer error.

With the subject standing with the heels on the floor, but as tall as possible, a rectangular block was placed perpendicular to the wall and flat on the subject's head. A mark corresponding to the height was carefully made on a stationary wallboard. The measurement was repeated in the afternoon by the same observer with the subject standing at the same site.

The collected data were thoroughly screened and entered into M S-Excel spread sheets and analysis was carried out. M eans of stature taken at different times of the day for 5 days for each subject were calculated. Differences in the morning and evening heights were recorded in millimeters and the mean was calculated. The calculated mean was analysed using SPSS statistical software.

\section{RESULTS}

Table 1: M eans of stature taken at separate times of the day for 5 days.

\begin{tabular}{|c|c|c|c|c|}
\hline \multirow{2}{*}{ Subject } & \multirow{2}{*}{ Age in years } & \multicolumn{2}{|c|}{ Stature in $\mathrm{mm}$ at } & Mean stature \\
\cline { 3 - 5 } & & $0900 \mathrm{hrs}$ & $1600 \mathrm{hrs}$ & difference in $\mathrm{mm}$ \\
\hline males & $15 \pm 2.1$ & $1671 \pm 102.2$ & $1658 \pm 101.91$ & $11 \pm 3.40$ \\
\hline females & $17 \pm 1.07$ & $1524 \pm 70.44$ & $1517.5 \pm 70.31$ & $6.5 \pm 2.40$ \\
\hline total & $16 \pm 1.58$ & $1572 \pm 109.35$ & $1566 \pm 107.86$ & $8 \pm 3.64$ \\
\hline
\end{tabular}

The data collected from the 60 subjects in the study group (30 males and 30 females) were analyzed. Table 1 presents the means of stature measured at separate times of the day for the 60 subjects. Table 2 presents the results of the paired sample t tests of the difference in the mean height of the participants at $0900 \mathrm{hrs}$ $(1584.53 \mathrm{~mm})$ and at $1600 \mathrm{hrs}(1576.25 \mathrm{~mm})$. The results show that there was a significant difference in height $(p=0001)$ between morning and evening among the participants. Table 3 shows the comparison of mean difference of height among males and females. Among males and females also there was significant $(p=.0001)$ 
difference. Graph 1 represents box plot gender wise comparison of stature.

Table 2: Paired Samples Statistics.

\begin{tabular}{|c|c|c|c|c|c|c|}
\hline & Mean & N & $\begin{array}{c}\text { Std. } \\
\text { Deviation }\end{array}$ & t & Df & $\begin{array}{c}\text { Sig. } \\
\text { (2-tailed) }\end{array}$ \\
\hline Height(mm) at 9:00Am & 1584.53 & 60 & 109.349 & \multirow{2}{*}{17.644} & 59 & 0.0001 \\
\hline Height(mm) at 4:00Pm & 1576.25 & 60 & 107.856 & & & \\
\hline
\end{tabular}

Table 3: Comparison of mean difference of height in the morning and evening of males and females.

\begin{tabular}{|c|c|c|c|c|c|c|c|}
\hline & Gender & $\mathrm{N}$ & $\begin{array}{c}\text { Mean } \\
\text { difference of } \\
\text { height }\end{array}$ & $\begin{array}{c}\text { Std. } \\
\text { Deviation }\end{array}$ & $\mathrm{t}$ & $\mathrm{df}$ & $\begin{array}{c}\text { Sig. } \\
\text { (2-tailed) }\end{array}$ \\
\hline $\begin{array}{l}\text { Difference in } \\
\text { Height }(\mathrm{mm})\end{array}$ & Male & 30 & 10.43 & 3.401 & 5.656 & 58 & 0.0001 \\
\cline { 2 - 8 } & Female & 30 & 6.13 & 2.403 & & \\
\hline
\end{tabular}

Graph 1: Box Plot comparing the stature in the morning and evening among males and females.

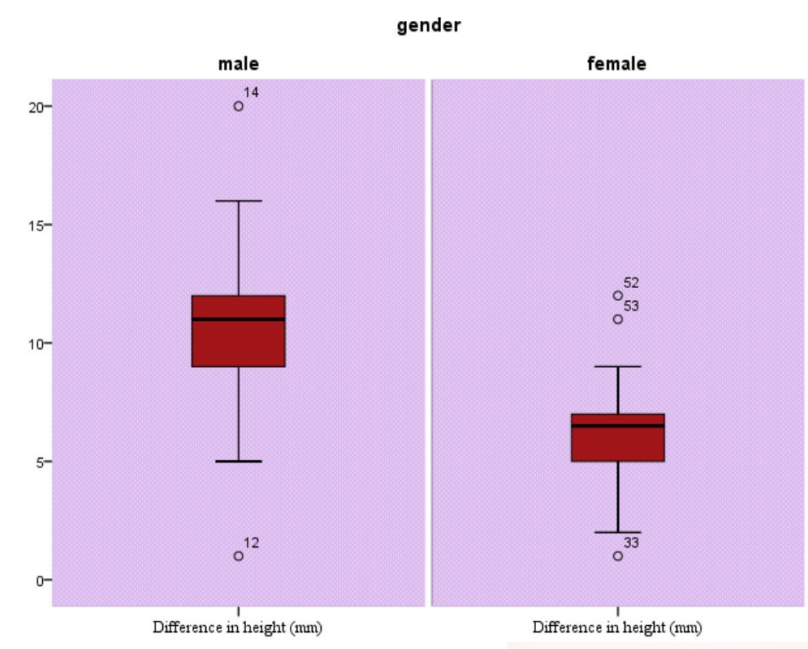

\section{DISCUSSION}

Anthropometric dimensions of stature are a quantitative measure of physical growth and development of an individual. Anatomically, it is a composite of linear dimensions of skull, vertebral column, pelvis and legs [15].

There is a definite association between stature and dimensions of various body segments as stated and the results are periodically used in anthropometric studies for physical growth and development of children, medico-legal investigations and personal documentation in forensic examinations by several scientists all over the world [16-19]. Almost all studies report that stature is maximum in the morning and less by $1.5 \mathrm{~cm}$ to $3.0 \mathrm{~cm}$ in the evening. The difference between recumbent length and stature within an individual has also received substantial attention in the literature $[20,21]$ but at the same time, intra-individual variation in stature has received little attention. Gender difference in diurnal variation as well has not been studied in detail. In the present study there is a significant diurnal difference in height between male and female. (Table 3). The mean height difference in male taken between 0900hrs and $1600 \mathrm{hrs}$ is $10.43 \mathrm{~mm}$ and the mean height difference in female $6.13 \mathrm{~mm}$. (Table3).

According to Voss and Bailey (1997) there is no further apparent decrement in stature occurs, once the person has been up for six or seven hours after rising [22], which doesn't support our study. Commonly used, standard stretched technique does not appear to reject the effects of diurnal stature loss. It simply increases the measure height. Some suggest that 'gentle upward pressure on the mastoid processes' could minimize the effects of diurnal variation in stature [23]. Indeed, these authors claim to have shown that using this technique, loss in stature between morning and afternoon, though not entirely eliminated, can be reduced to a maximum of $0.46 \mathrm{~cm}$. In the present study the diurnal variation in height for both male and female show marked increase when compared to previous studies. The increase in male can be attributed to their built and weight and while comparatively female the diurnal variation in height is less the reason may probably be cited with the explanation from the genetics; e.g. females are generally better canalized thus show less diurnal variation in stature. This may also be attributed to the fact that if one assumes that the females are not as involved as their male counterparts in activities that result in compression of the vertebral column and other joints in the body [15]. Thus, from the present study and previous studies, it is possible to say that height of a person shows diurnal variation irrespective of gender.

The amount and extent of variation depends upon the time of measuring the height and varies from individual to individual. Diurnal stature loss can be a problem in short term longitudinal studies, in which apparent changes might simply reflect variations in the time of the day at which the measurement was taken [24]. This diurnal loss in stature may be attributed to the compression of fibrous discs of cartilage that separate the vertebrae. With the forces of gravity imposed by standing, walking and involving 
in physical activity, the discs are gradually compressed [25]. The greater proportion of the change occurs in the vertebral column than in any other part of the body. Some agree that this is due not only to inter-vertebral shortening but also to bending of the vertebral column during the daytime [26] and still others opine the diurnal variation in height is mainly due to loss of fluid from the inter-vertebral discs rather than postural changes (Fairbank, 1998).

\section{CONCLUSION}

Diurnal variation in linear height of an individual may substantially affect the reliability of height data and careful consideration should be given to the time of measurement and also take in to account of the gender difference. Thus the present study will help the scientists, researchers and clinicians engaged in conducting community based surveys involving stature as measurement and for making reference data pertaining to growth, development and nutritional studies, for personal identification in forensic examinations as well as for recruitment of individuals for service.

\section{Conflicts of Interests: None}

\section{REFERENCES}

[1]. Conroy, R. W. T. L. \& Mills, J. N. Human Circaadian Rhythms. London: Churchill 1970.

[2]. Wasse J. Part Of A Letter From The Reverend M rwasse, Rector Of Aynho In Northamptonshire, To Dr Mead, Concerning The Difference In The Height Of A Human Body, Between M orning And Night. Philosophical Transactions Of The Royal Society Of London 1726;33:87-8.

[3]. Redfield Je, M eredith Hv. Changes In The Stature And Sitting Height Of Preschool Children In Relation To Rest In The Recumbent Position And Activity Following Rest. Child Dev 1938;9:293-302.

[4]. Boyd E. The Experimental Error Inherent In M easuring The Growing Human Body. Am J Phys Anthropol1929;13:390- 432.

[5]. Nylin G. Periodical Variations In Growth, Standard M etabolism, And Oxygen Capacity Of The Blood In Schoolchildren. Acta Med Scand1929;31(Suppl):207.

[6]. Palmer Ce. Diurnal Variations of Height And Weight In The Human Body During Growth. Anat Rec 1930;45:234-5.

[7]. Strickland Al, Shearin Rb. Diurnal Height Variation In Children.Pediatrics1972;80:1023-5.

[8]. Whitehouse Rh, Tanner Jm, Healy M jr. Diurnal Variation In Stature And Sitting Height In 12-14-Year-Old Boys. Ann Hum Biol1974;1:103-6.
[9]. Buckler Jmh. Variations in Height Throughout The Day. Arch Dis Child 1978;53:762.

[10]. Ashizawa K, Kawabata M. Daily Measurements of The Heights of Two Children from June 1984 To M ay 1985. Ann Hum Biol 1990;17:437-43.

[11]. Palmer, C.E. : Diurnal Variation of Height and Weight In The Human Body During Growth. Anat. Rec. 1930;45:234- 235.

[12]. Lampl M. Further Observations on Diurnal Variation In Standing Height. Ann Hum Biol 1992;19:8790.

[13]. Kazarian L E 1974 Nasa (Unpublished Data) Usa. (Cited By Grieve “1981) Keller T S, Spengler D M, Hansson TH 1987 Mechanical

[14]. Adams M A., Dolan P^, Hutton W C. Diurnal Variations In The Stresses On The Lumbar Spine 1987; 12:130-137.

[15]. Krishan K, Vij K. Diurnal variation of stature in three adults and One Child. Anthropologist 2007;9(2):113117.

[16]. jantz, R.L., Hunt, D.R. and Meadows, L.: The measure and mis-measure of the Tibia: Implications for stature estimation. J. Forensic Sci. 1995;40(5):758-761.

[17]. Jason, D.R. and Taylor, K.: Estimation of stature from the length of the cervical, thoracic and lumber segments of the spine in American Whites and Blacks. J. Forensic Sci. 1995;40(1):59-62.

[18]. Klepinger, L.L.: Stature, maturation variation and secular trends in forensic anthropology. J. Forensic Sci. 2001;46(4):788-790.

[19]. Vashisht, R.N., Krishan, K. and Kaur, C.: Growth and nutritional status of school-going Punjabi rural Ropar girls. Pb. Univ. Res. Jour. Sci. 2003;53:35-48.

[20]. Roche, A.F. and Davila, G.H.: Differences between recumbent length and stature within individuals. Growth 1974;38:313-320.

[21]. Krishan, K. and Sharma, J.C.: Intra-individual difference between recumbent length and stature among growing children. Indian J. Pediatr. 2002;69:565569.

[22]. Voss, L.D. and Bailey, B.J.R.: Diurnal variation in stature: Is stretching the answer ? Arch. Dis. Child. 1997; 77:319-322.

[23]. Whitehouse, R.H., Tanner, J.M . and Healy, M .J.R.: Diurnal variation in stature and sitting height in 1214-year-old boys. Ann. Hum. Biol.1974;1:103-106.

[24]. Malina, R.M . and Beunen, G. M onitoring of growth and maturation. In: The child and Adolescent Athlete- Volume VI of the Encyclopedia of Sports M edicine O. Bar-or (Ed.). IOC M edical Commission Publication in Collaboration with international Federation of Sports Medicine;1996:647-672.

[25]. Malina, R.M .: Anthropometry. In: Physiological Assessment of Human Fitness. P.J. M aud and C. Foster (Eds.). Human Kinetics;1995;205-219.

[26]. Hattori, K. and Nishio, F.: Diurnal change of the relief on the body back surface. Japanese J. Hum. Posture 1982;2:73-78.

[27]. Fairbank, J.: Height measurements and stretching. Lancet 1998;351:1212. 